\title{
Video Animasi Sebagai Media Pembelajaran Efektif bagi Siswa Sekolah Dasar di Masa Pandemi COVID-19
}

\author{
Zainal Abidin Achmad ${ }^{1}$, Muhammad Iqbal Dwi Fanani ${ }^{2}$, Ghifari Zaka Wali ${ }^{3}$, Rizkiyatul \\ Nadhifah ${ }^{4}$, Nadya Aisyah Nurdiyana ${ }^{5}$, Marizka Distya Anastasia ${ }^{6}$ \\ 1,2,3,4,5,6 Universitas Pembangunan Nasional "Veteran" Jawa Timur, Surabaya, Indonesia \\ Contact: z.abidinachmad@upnjatim.ac.id
}

\begin{abstract}
This article's background is the impact of the Coronavirus Disease 2019 (COVID-19) pandemic on the process of implementing school learning that has turned online. This article contains the process of making animated video learning media using the Powtoon application. Animated video material is the National Examination subject (Indonesian, Science, and Mathematics) for elementary school students in grades one to six. The data collection method used interviewing students, parents, teachers, village heads, PKK administrators, and youth organizations. By analyzing the problems then accomplished by making animated videos that suitable to the syllabus for each subject. The animated video is uploaded to the Sidokumpul Village Community Service Program's official Youtube channel to be accessed by all target elementary students and the wider community. Making animation is to provide learning innovation for elementary school teachers and students in Sidokumpul village and attract interest in learning. The stages of making animated videos consist of pre-production, production, and postproduction. Animated videos can accelerate elementary students' understanding of the subject matter. Moreover, parental involvement in online learning provides many positive things for relationships between family members and student personality development.
\end{abstract}

Keywords: animated video, COVID-19, learning innovation, online learning

\begin{abstract}
ABSTRAK
Latar belakang artikel ini adalah dampak pandemic Coronavirus Disease 2019 (COVID-19) pada proses pelaksanaan pembelajaran sekolah yang berubah menjadi daring. Artikel ini berisikan proses pembuatan media pembelajaran video animasi dengan aplikasi Powtoon. Materi video animasi adalah mata pelajaran Ujian Nasional (Bahasa Indonesia, Sains, dan Matematika) bagi murid sekolah dasar kelas satu hingga enam. Metode pengumpulan data menggunakan wawancara kepada para siswa, orangtua, guru, kepala kelurahan, pengurus PKK dan pengurus karang taruna. Setelah menganalisis permasalahan, solusinya adalah pembuatan video animasi yang disesuaikan dengan silabus pada tiap mata pelajaran. Video animasi diunggah ke kanal Youtube resmi KKN Kelurahan Sidokumpul untuk diakses seluruh siswa SD binaan dan masyarakat luas. Tujuan pembuatan animasi adalah memberikan inovasi pembelajaran bagi guru dan siswa sekolah dasar di kelurahan Sidokumpul, dan untuk menarik minat belajar. Tahapan pembuatan video animasi melalui pra produksi, produksi dan pasca produksi. Video animasi mampu mempercepat pemahaman siswa SD terhadap materi pelajaran. Keterlibatan orangtua dalam pembelajaran daring memberikan banyak hal positif bagi hubungan antar anggota keluarga dan perkembangan kepribadian siswa.
\end{abstract}

Kata Kunci: COVID-19, inovasi pembelajaran, pembelajaran daring, video animasi

\section{Pendahuluan}

Pendidikan merupakan topik yang selalu menarik dan aktual untuk dibicarakan. Pendidikan juga merupakan masalah yang kompleks dan tidak akan pernah terselesaikan sepenuhnya. Banyak aspek dan elemen yang kompleks untuk mengurai masalah pendidikan 
agar dapat memberikan jawaban yang memuaskan bagi berbagai pihak (Mardliyah \& Achmad, 2017). Hal paling mudah bagi warga negara Indonesia untuk memahami kata pendidikan adalah dengan mengacu pada Undang-Undang Nomor 20 Tahun 2003 tentang Sistem Pendidikan Nasional. Terutama pada pasal 1 , ayat 11 , dan pasal 1 ayat 12 . Pasal 1 ayat 11 menyebutkan bahwa pendidikan formal adalah jalur pendidikan yang terstruktur dan berjenjang, yang terdiri dari pendidikan dasar, pendidikan menengah, dan pendidikan tinggi. Sedangkan pada pasal 1 ayat 12 disebutkan bahwa pendidikan nonformal merupakan jalur pendidikan di luar pendidikan formal yang dapat dilaksanakan secara terstruktur dan berjenjang.

Belum lagi Indonesia mampu mengatasi kesenjangan pendidikan agar dapat diakses seluruh warga Negara secara murah dan berkualitas. Dunia mendapatkan bencana pandemic COVID-19, sebuah kondisi yang memaksa seluruh sendi kehidupan mengalami stagnasi, termasuk pendidikan. Hampir seluruh sekolah di seluruh negeri ditutup dan meniadakan proses belajar mengajar tatap muka. Seluruh pembejalaran "terpaksa" harus berlangsung secara daring. Larangan melakukan tatap muka dan bertemu secara berkelompok membuat manusia seolah bukan menjadi makhluk sosial. Sementara tuntutan terhadap lembaga pendidikan sebagai ladang bagi tumbuhnya benih manusia berilmu dan tempat mengasah kemampuan berpikir tidak pernah turun. Sekolah harus tetap menjadi miniatur sosial, sebagai tempat berinteraksi berbagai kelas sosial di masyarakat (Yulianingsih et al., 2018).

Sekolah harus tetap memiliki fungsi penting untuk melatih keterampilan dan kecerdasan sosial siswanya. Manusia menggantungkan hidupnya dengan mengandalkan teknologi, terutama internet. Jaringan internet menjadi penyelamat peradaban manusia pada masa pandemi COVID-19. Interaksi dan komunikasi masih dapat terjalin, bahkan semakin banyak inovasi teknologi komunikasi berbasis internet. Media komunikasi semakin berkembang ke arah konvergensi. Bentuk suratkabar, radio, dan televisi menjadi semakin tipis perbedaannya dan cenderung menjadi saling tumpang tindih pendefinisiannya (Achmad., 2019; Achmad, 2020; Candrasari, 2020).

Sejak wabah COVID-19 melanda Indonesia, pemerintah telah melakukan berbagai cara untuk meminimalisir penyebarannya, salah satunya melalui surat edaran Kementerian Pendidikan dan Kebudayaan (Kemendikbud) nomor 4 tahun 2020 tentang pelaksanaan kebijakan pendidikan dalam masa darurat penyebaran COVID-19 dengan mengikuti proses belajar dari rumah melalui pembelajaran daring atau jarak jauh. Akibatnya terjadi perubahan yang sangat tiba-tiba dan cenderung mengagetkan baik dari sisi guru maupun siswa karena terjadi perubahan budaya belajar yang mendadak. Kekagetan budaya ini salah satunya berdampak kepada terganggunya sistem penyesuaian sosial dalam pembelajaran, terganggunya motivasi berprestasi, dan interaksi pembelajaran menjadi tidak optimal (Ernofalina, 2017). Padahal kegiatan pembelajaran yang kondusif adalah kegiatan yang membentuk suasana interaksi yang menyenangkan, mendorong anak untuk mencoba, terjadi dialog tanpa batas, dan anak didik mendapatkan kesempatan yang luas untuk mengekspresikan diri dalam melejitkan potensi diri yang mereka miliki (Agustin et al., 2020).

Lebih jauh pembelajaran yang efektif akan membekali anak dengan pengalaman menyenangkan dan bermakna yang akan mengendap dalam pikiran anak sepanjang masa 
sebab belajar yang baik pada dasarnya adalah pembelajaran yang memberikan anak pengalaman yang menantang, kreatif dan konstruktif yang tujuan akhirnya adalah membantu anak untuk dapat memecahkan masalah dimasa yang akan datang (Daulae, 2014). Pembelajaran yang kondusif ini semakin sulit terjadi karena adanya pandemi COVID-19 yang menyebabkan guru sebagai pengajar utama mengalami kesulitan dan mengalami berbagai kendala untuk dapat menciptakan situasi pembelajaran yang kondusif. Proses pembelajaran harus terus berlangsung, di balik carut marutnya informasi seputar pandemic COVID-19 dan kesimpangsiuran kepercayaan publik kepada pemerintah dan media massa (Indiyati et al., 2020; Teluma, 2020).

Proses belajar mengajar tidak terlepas dari strategi, metode dan media yang digunakan guru (Panjaitan et al., 2020). Pembelajaran positif merupakan realisasi dari aksi guru untuk unjuk profesionalisme dengan berbasis kepada pengalaman dan praktek yang mereka lakukan dan miliki, jika ini terkendala maka akan sulit diperoleh peningkatan mutu pembelajaran apalagi jika unsur-unsur interaksi pedagogik dalam pembelajaran ikut memudar (Gore et al., 2017). Dalam hal ini, pembelajaran yang efektif akan sulit tercapai dikalangan siswa sekolah dasar karena siswa sekolah dasar masih perlu dibimbing dan diawasi ketika belajar atau mengerjakan tugas guna mencapai standar kompetensi yang telah dibuat oleh pihak sekolah ataupun pihak Kementerian Pendidikan. Tidak dapat terbantahkan bahwa peran guru dalam pembelajaran memegang posisi yang sangat penting, strategis dan bahkan menjadi kunci untuk mencapai pembelajaran yang bermutu dan efektif (Ronkainen et al., 2019).

Terkait dengan perilaku mengajar yang berpusat pada anak, adalah menyampaikan pembelajaran dengan interaksi yang mendidik antara guru dengan anak didik sehingga tercipta suasana yang demokratis. Selain itu tersedia metode mengajar yang variatif, guru memiliki kecakapan profesional, bahan ajarnya sesuai dengan perkembangan anak, lingkungan yang aman dan nyaman. Untuk menarik keterlibatan aktif siswa dibutuhkan sarana yang menunjang efektivitas belajar (Yusuf, 2017). Untuk mewujudkan pembelajaran yang efektif maka guru sebagai tokoh utama dalam pembelajaran diwajibkan menjadi guru yang efektif pula, yaitu guru yang menggunakan waktu mengajar secara maksimal, menyampakan materi dengan metode yang bervariasi, memantau proram dan kemajuan melalui penilaian peserta didik, merancang kesemparan belajar bagi peserta didik untuk menerapkan pengalaman belajar,bersedia mengulang materi ketika anak belum memahaminya, menetapkan target belajar untuk setiap anak (Setyosari, 2017).

Salah satu bentuk pembelajaran alternatif yang dapat dilaksanakan selama masa darurat COVID-19 adalah dengan sistem pembelajaran online. Pembelajaran online merupakan pembelajaran yang menggunakan jaringan internet dengan aksesibilitas, konektivitas, fleksibilitas, dan kemampuan untuk memunculkan berbagai jenis interaksi pembelajaran (Moore et al., 2011). Beberapa penelitian menunjukkan bahwa penggunaan internet dan teknologi multimedia mampu merombak cara penyampaian pengetahuan dan dapat menjadi alternatif media pembelajaran untuk mempromosikan tradisionalitas, nilai moralitas, dan agama (Achmad., 2019; Achmad, 2020). 
Pembelajaran online pada pelaksanaannya membutuhkan dukungan perangkatperangkat mobile seperti telepon pintar, tablet dan laptop yang dapat digunakan untuk mengakses informasi dimana saja dan kapan saja (Gikas \& Grant, 2013). Penggunaan mobilitas teknologi memiliki kontribusi besar dalam pencapaian tujuan pembelajaran jarak jauh. Berbagai media juga dapat digunakan untuk mendukung pelaksanaan pembelajaran secara online. Misalnya kelas-kelas virtual menggunakan layanan Google Classroom, Edmodo, dan Schoology. Pembelajaran secara online bahkan dapat dilakukan melalui media social seperti Facebook dan Instagram (Mushlihah et al., 2018; Nurkamid et al., 2010; Rubiyati, Muhamad Asrori, 2017).

Pada saat ini, Smartphone atau Android menjadi media utama dalam proses belajar mengajar. Ditambah dengan kebijakan pembelajaran secara daring yang diberlakukan oleh Pemerintah Kabupaten Gresik sebagai upaya memutus rantai penularan pada COVID-19 ini. Di sisi lain, pembelajaran secara daring seringkali membuat anak-anak menjadi jenuh dan bosan, sehingga siswa jadi tidak bisa menyerap dengan baik materi yang disampaikan oleh guru. Selain itu juga tidak dapat berinteraksi dan bermain bersama teman-temannya sehingga mereka mudah stres. Sehingga tidak heran dalam kondisi seperti ini banyak anak yang enggan untuk belajar dan lebih memilih untuk bermain. Oleh karena itu, inovasi pembelajaran daring perlu dilakukan oleh seluruh tenaga pengajar agar siswa-siswi tidak merasa bosan dalam proses pembelajaran. Optimalisasi pemanfaatan teknologi dalam pembelajaran dengan menggunakan video animasi menjadi salah satu kegiatan pengabdian masyarakat yang dilakukan untuk mengatasi masalah pendidikan akibat COVID-19.

Untuk itulah salah satu bentuk kegiatan sosial yang dilakukan oleh mahasiswa Universitas Pembangunan Nasional "Veteran" Jawa Timur adalah mendarmabaktikan ilmu yang dikuasainya kepada masyarakat terdampak COVID-19 di bidang pendidikan. Proses pembelajaran daring yang dikeluhkan orangtua, guru dan siswa Sekolah Dasar menjadi sasaran utama yang mendapat perhatian kelompok mahasiswa ini. Sebagai gabungan berbagai bidang keilmuan (Sains dan Sosial Humaniora), bekerjasama membuat video animasi sebagai inovasi media pembelajaran untuk mata pelajaran ujian nasional (Bahasa Indonesia, Sains, dan Matematika). Adapun wilayah yang menjadi sasaran kelompok ini adalah Kelurahan Sidokumpul yang menjadi salah satu daerah sasaran dalam kegiatan KKN Regular COVID-19. Konsep baru dalam pelaksanaan KKN yang dilaksanakan sebagai bentuk implementasi Peraturan Pemerintah dengan melakukan pembatasan gerak kegiatan yang bersifat massal di lingkungan masyarakat. Sehingga banyak program KKN tahun 2020 ini dilangsungkan dengan online-based program.

Tantangan yang harus dihadapi Dosen Pendamping Lapangan dengan para mahasiswa bimbingannya adalah pemetaan permasalahan dan kebutuhan masyarakat terdampak COVID19. Divisi inovasi pembelajaran daring yang bertugas di Kelurahan Sidokumpul memutuskan untuk merancang dan memutuskan program yang memiliki dampak inovatif bukan hanya bagi siswa dan guru Sekolah Dasar di Kelurahan Sidokumpul melainkan juga seluruh Indonesia. Karena luaran video animasi produksi divisi inovasi pembelajaran daring ini singgah di Youtube dan bermanfaat untuk masyarakat luas. 


\section{Metode}

Sebelum merencanakan kegiatan, seluruh anggota divisi inovasi pembelajaran daring menggali data dengan melakukan wawancara kepada perangkat kelurahan, pengurus PKK, karang taruna, para guru, dan anak-anak usia sekolah dasar. Informasi yang dikumpulkan adalah mengenai berbagai macam kesulitan yang dihadapi dalam melaksanakan proses belajar mengajar terutama untuk implementasi kurikulum baru yang menyesuaikan keadaan pandemi COVID-19. Praktik keharusan belajar dari rumah masing-masing dengan metode daring tidak semudah yang direncanakan dalam protimgram pemerintah.

Tim ini juga menggali data adalah tentang praktik pembelajaran daring yang telah dilakukan oleh para guru yang mengajar di Sekolah Dasar Sidokumpul. Selain itu, tim melakukan identifikasi tentang dukungan orangtua, pengurus RT/RW dan perangkat kelurahan terhadap proses pembelajaran daring agar anak-anak tetap dapat belajar dengan giat dalam kondisi pandemi.

Setelah mengumpulkan seluruh permasalahan, tim melakukan identifikasi kualifikasi personil tim. Kemampuan-kemampuan apa saja yang dimiliki oleh tiap anggota. Sehingga tim memutuskan untuk memproduksi video-video animasi pembelajaran. Kondisi yang mendukung adalah, (1) wilayah Kelurahan Sidokumpul berada dalam area jaringan sinyal 3G dan 4G yang sangat baik dari semua provider GSM. (2) pihak RT dan RW telah menyiapkan hotspot untuk akses wi-fi secara gratis bagi seluruh anak usia sekolah dasar untuk belajar. Titik pusat hotspot diletakkan di Posko Kampung Tangguh Semeru, untuk memudahkan warga yang kesusahan ekonomi untuk menggunakan fasilitas wifi apabila diperlukan.

Metode komunikasi antara anggota divisi inovasi pembelajaran daring dengan seluruh anak SD di Keluarahan Sidokumpul menggunakan aplikasi WhatsApp. Selain untuk komunikasi jadwal pembelajaran offline dan konsultasi pelajaran, grup tersebut juga digunakan untuk berbagi alamat website tempat penyimpanan video animasi yang akan dipelajari. Video-video yang telah jadi, diunggah ke akun YouTube resmi KKN 45 Sidokumpul untuk memudahkan para anak-anak SD di Kelurahan Sidokumpul dan masyarakat luas untuk melihat dan belajar materi pelajaran Ujian Nasional Sekolah Dasar.

\section{Hasil dan Pembahasan}

Beberapa permasalahan yang ditemukan antara lain: (1) tidak semua anak mempunyai handphone untuk berkomunikasi atau melakukan pembelajaran daring sehingga mereka menggunakan handphone orang tua mereka untuk menghadiri kelas daring yang diselenggarakan oleh pihak sekolah. (2) tidak semua guru memiliki kapabilitas untuk membuat media pembelajaran daring. (3) banyaknya waktu luang anak-anak, selepas jam pelajaran, sehingga lebih banyak digunakan untuk bermain bersama teman-teman yang bertempat tinggal berdekatan. Bermain bersama berpotensi berkumpulknya anak-anak dalam jumlah banyak dan hal ini menimbulkan kekhawatiran orangtua. Sementara orangtua masih bekerja, pengawasan pada anak-anak saat bermain sangat lemah.

Identifikasi masalah tersebut menjadi dasar bagi tim divisi inovasi pembelajaran daring untuk melakukan kombinasi program pembelajaran antara offline dan online. Untuk pembelajaran offine, seluruh anak usia sekolah dasar di Keluarahan Sidokumpul, dibagi ke 
dalam grup kelas (1-3) dan kelas (4-6). Tujuannya agar tim lebih mudah memberi materi dan anak-anak juga lebih mudah untuk menyesuaikan materi dari divisi inovasi pembelajaran daring dan tema materi pelajaran yang diberikan oleh sekolah. Sebagi sarana komunikasi tim divisi inovasi pembelajaran daring dengan anak-anak, adalah dengan menggunakan grup WhatApp untuk mengkomunikasikan jadwal pelajaran tambahan di beberapa lokasi yang disepakati, antara lain Balai Kelurahan, Posko Kampung Tangguh, Rumah Penduduk, atau Taman Baca Alquran yang ada di Masjid.

Sedangkan untuk pembelajaran daring, konsep yang dipilih adalah pembuatan video animasi yang menarik agar anak-anak dapat melihat visualisasi materi pelajaran. Materi video dirancang sesuai tingkat pemahaman tiap-tiap jenjang kelas di Sekolah Dasar. Pada jam-jam tertentu yang telah disepakati, anak-anak pada jenjang kelas tertentu diarahkan untuk melihat dan mempelajari video yang ada di Youtube, selama 15 menit. Selama menyaksikan video tersebut, anak-anak wajib didampingi orangtuanya. Setelah menyaksikan video, ada quiz yang relevan dengan materi video, dan harus dijawab anak-anak melalui grup WhatsApp.

Selama sebulan (1 hingga 28 Juli 2020) seluruh proses pembelajaran daring berlangsung. Dan akhir 3 hari terakhir masa pengabdian, anggota divisi menuju tiga titik pertemuan dengan anak-anak SD binaan. Tujuannya adalah melakukan quiz untuk menilai tingkat pemahaman anak-anak terhadap materi pelajaran yang sudah dipelajari selama satu bulan. Bagi anak-anak yang berhasil menjawab dengan tepat, diberikan hadiah berupa paket makanan dan minuman sehat. Bersama Dosen Pembimbing Lapangan, tim divisi inovasi pembelajaran daring ini memberikan motivasi belajar kepada anak-anak SD dan mempersembahkan seluruh video tersebut dan memberikan penyuluhan tentang pembuatan video animasi bagi para guru Sekolah Dasar di Keluarahan Sidokumpul. Tujuannya agar para guru, orangtua, anak-anak tetap memiliki semangat untuk melangsungkan proses belajar mengajar di tengah kondisi pandemi.

\section{Proses Pembuatan Video Animasi Tahap Pra Produksi}

Tim melakukan observasi lapangan di Kelurahan Sidokumpul, Kecamatan Gresik, Kabupaten Gresik untuk melakukan pemetaan permasalahan terkait kebutuhan yang diperlukan oleh masyarakat. Salah satunya mengatasi kebosanan anak-anak mengikuti proses belajar mengajar secara daring. Kemudian melakukan perencanaan program pembelajaran yang ditujukan kepada anak-anak usia Sekolah Dasar kelas 1 hingga kelas 6 di Kelurahan Sidokumpul.

Langkah selanjutnya adalah berdiskusi dengan para guru Sekolah Dasar untuk merancang pembuatan silabus agar sesuai dengan rencana pembelajaran semester pada tiaptiap mata pelajaran. Hal ini untuk memudahkan tim untuk membuat video yang sesuai dengan tema-tema bahasan pada tiap-tiap mata pelajaran. Juga untuk memudahkan disain visualisasi animasi agar siswa SD lebih mudah memahami materi.

\section{Tahap Produksi}

Setelah pembuatan silabus telah diselesaikan, dilanjutkan dengan langkah pembuatan video animasi. Animasi adalah rangkaian gambar yang membentuk sebuah gerakan. Salah satu keunggulan animasi dibanding media lain seperti gambar statis atau teks adalah kemampuannya untuk menjelaskan perubahan keadaan tiap waktu. Hal ini terutama sangat membantu dalam menjelaskan prosedur dan urutan kejadian (Dina, 2011). Dengan adanya software-software pembuat animasi seperti Adobe Flash, Adobe Director, Swift 3D, 3D Studio $M X$, dan beberapa lainnya. Ataupun melalui web pembuat animasi seberti Powtoon, Animaker, dan Filmora, yang menyediakan kemudahan pembuatan animasi sebagai alat pembelajaran. 
Sehingga saat ini, tidak lagi memerlukan keahlian khusus dan biaya tinggi. Bagaimanapun juga membuat animasi, tetap memerlukan waktu yang tidak sedikit, dan yang terpenting adalah keterampilan tambahan, yaitu seni dan kreativitas.

Tahapan ini benar-benar menuntut anggota divisi inovasi pembelajaran daring untuk mencurahkan seluruh kreativitas dan ketrampilan disain audiovisual. Berdasarkan hasil wawancara dengan siswa SD di Kelurahan Sidokumpul, hampir semua lebih memilih media audio visual sebagai gabungan unsur suara dan unsur penglihatan. Media audiovisual dianggap yang lebih menarik bagi siswa SD apabila digunakan dalam proses pembelajaran.

Gambar 1: Tampilan awal Powtoon

Pembuatan video animasi menggunakan aplikasi Powtoon sebagai tools yang bisa

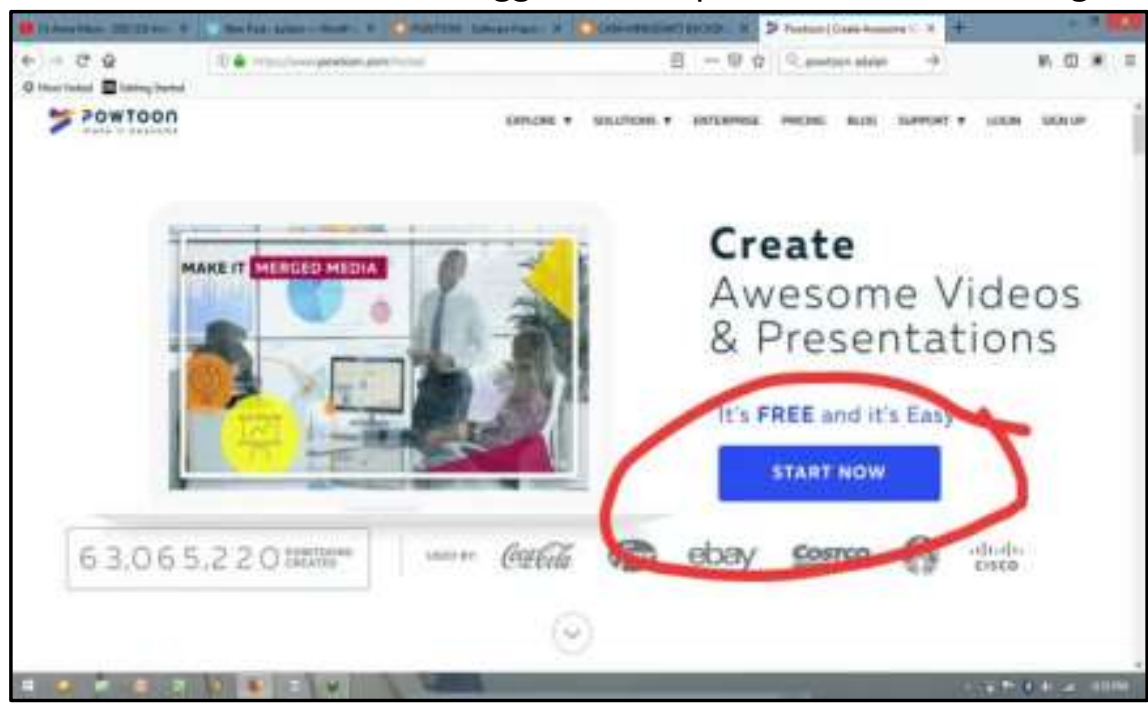

menghasilkan video berkualitas. Berikut ini adalah cara pembuatan video melalui Powtoon :

1. Buka laptop atau Personal Computer (PC) kemudian nyalakan dengan memastikan laptop atau PC terhubung pada koneksi internet yang kuat.

2. Buka jendela internet pada laptop atau PC, dapat menggunakan Mozilla Firefox, Google Chrome atau yang lainnya.

3. Search Powtoon pada kolom pencarian.

4. Kemudian pada layar computer akan muncul halaman awal aplikasi Powtoon, kemudian klik Start Now (gambar 1). Pada saat itulah aplikasi Powtoon dapat dijalankan.

5. Setelah itu muncul halaman permintaan pembuatan akun (gambar 2). Pengguna diminta

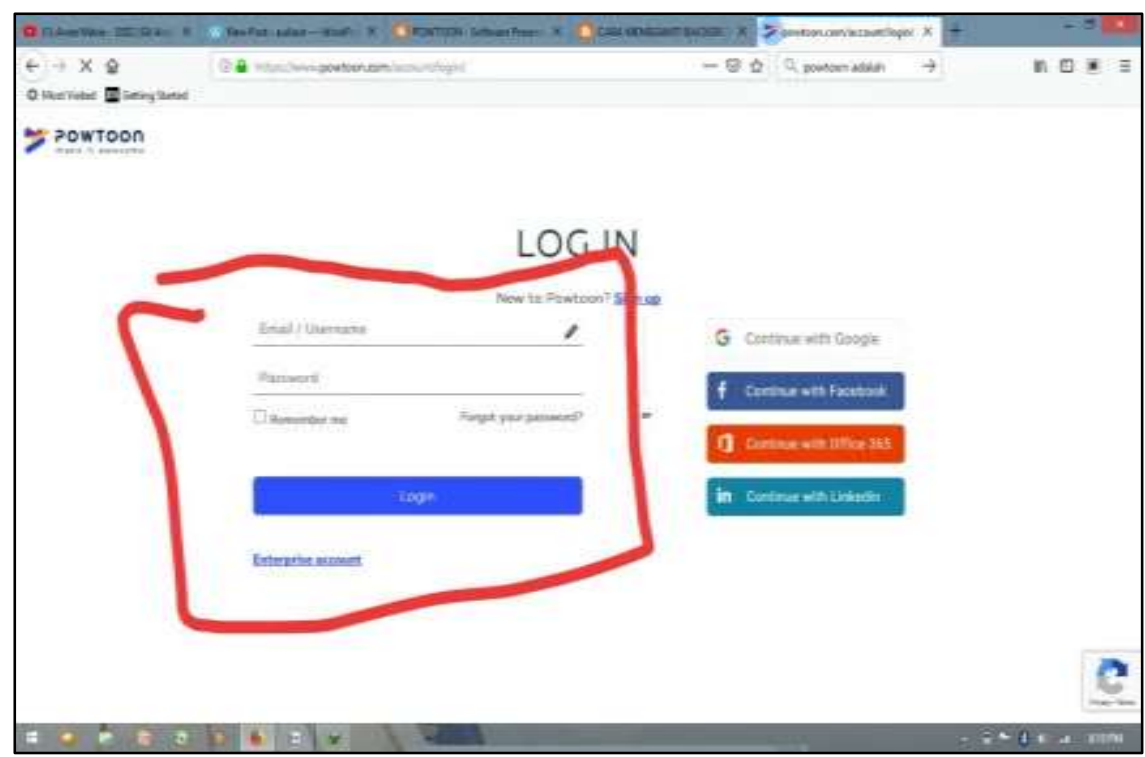


memasukkan e-mail beserta password e-mail untuk membuat akun Powtoon. Atau melakukan login menggunakan akun google. facebook, office, atau linkedin.

Gambar 2: Tampilan login pada Powtoon

6. Setelah berhasil memasuki aplikasi Powtoon, layar komputer pengguna akan muncul berbagai pilihan template dan tema. Pengguna dapat menggunakan template atau tema yang telah disediakan atau dapat membuat template sendiri. Apabila tidak menginginkan tema yang tersedia, pengguna dapat menutup laman tersebut dengan meng-klik tanda silang $(X)$ yang ada pada sudut kanan atas layar.

7. Pada bagian bawah layar terdapat kotak biru bertuliskan Blank Powtoon. Pengguna dapat meng klik kotak biru tersebut untuk membuat template sesuai keinginan pengguna (gambar 3). Setelah klik kotak bertuliskan Blank Powtoon maka tampilan layar akan berubah menuju kesiapan editing.

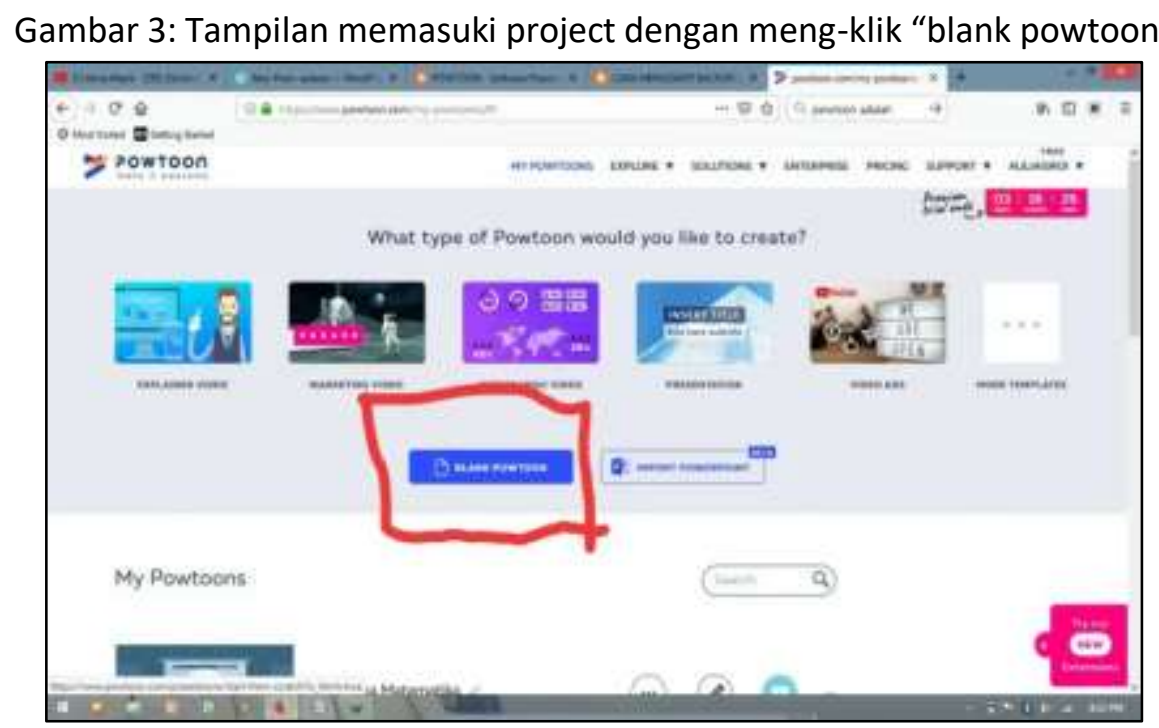

8. Setelah laman Blank Powtoon muncul (gambar 4), maka sudah dapat membuat video dengan sesuai keinginan masing-masing. Fitur-fitur yang dimiliki Powtoon terletak pada sisi kanan, dengan fitur-fitur tersebut dapat membuat video sesuai dengan selera dan kreativitas masing-masing.

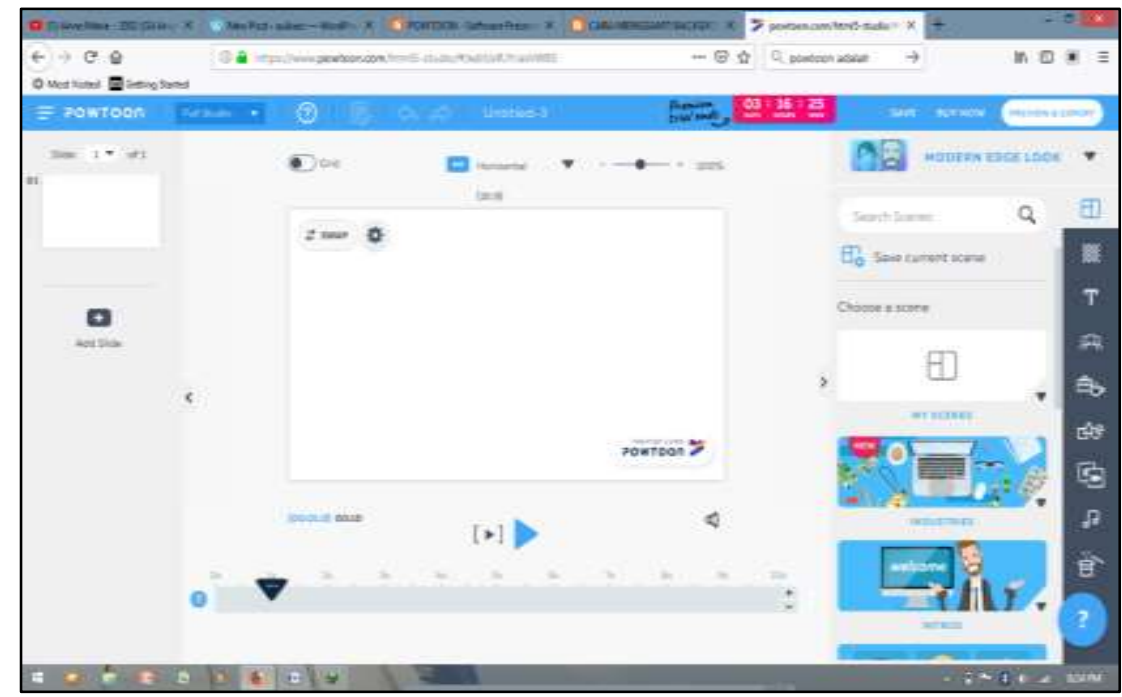


Pilihan fitur terdapat dalam kolom berwarna hitam, dengan berbagai simbol. Setiap simbol fitur telah dilengkapi dengan keterangan kegunaan fitur, apabila tanda panah (cursor) diarahkan pada simbol-simbo tersebut. Misalkan pada simbol nomor 2 (dua) dari atas, ada fitur dan keterangan Background, maka saat klik pada fitur tersebut, akan muncul berbagai Background atau latar belakang untuk slide yang nantinya akan menjadi video.

9. Untuk menambahkan slide, maka cukup klik pada bagian "Add Slide" yang terletak pada bagian kiri (gambar 5). Bertujuan untuk memperbanyak slide sesuai kebutuhan.

10. Apabila akan melakukan pengatuan waktu video, klik tanda tambah (+) untuk melakukan penambahan durasi waktu dan klik tanda kurang (-)untuk melakukan pengurangan waktu. Tanda tersebut terdapat pada bagian kanan bawah layar editing video.

Gambar 5: Tampilan add slide pada Powtoon

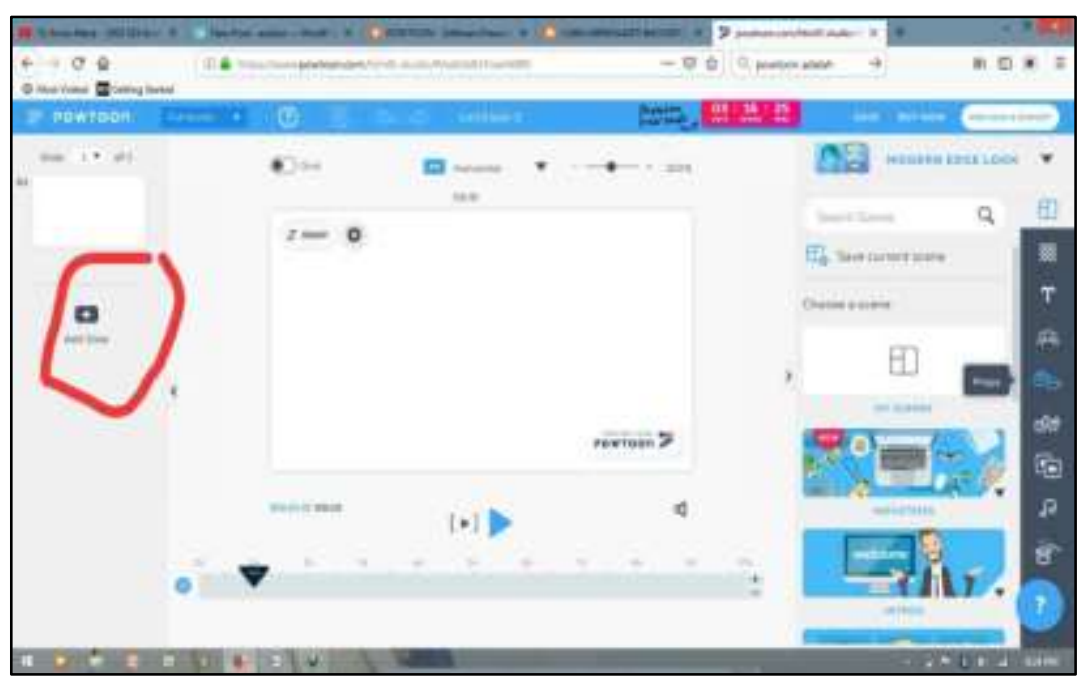

11. Pada saat selesai membuat video maka klik "save" yang terdapat pada pada bagian kanan atas, disamping tulisan Buy Now (gambar 6). Setelah klik save, maka animasi Powtoon akan tersimpan secara otomatis.

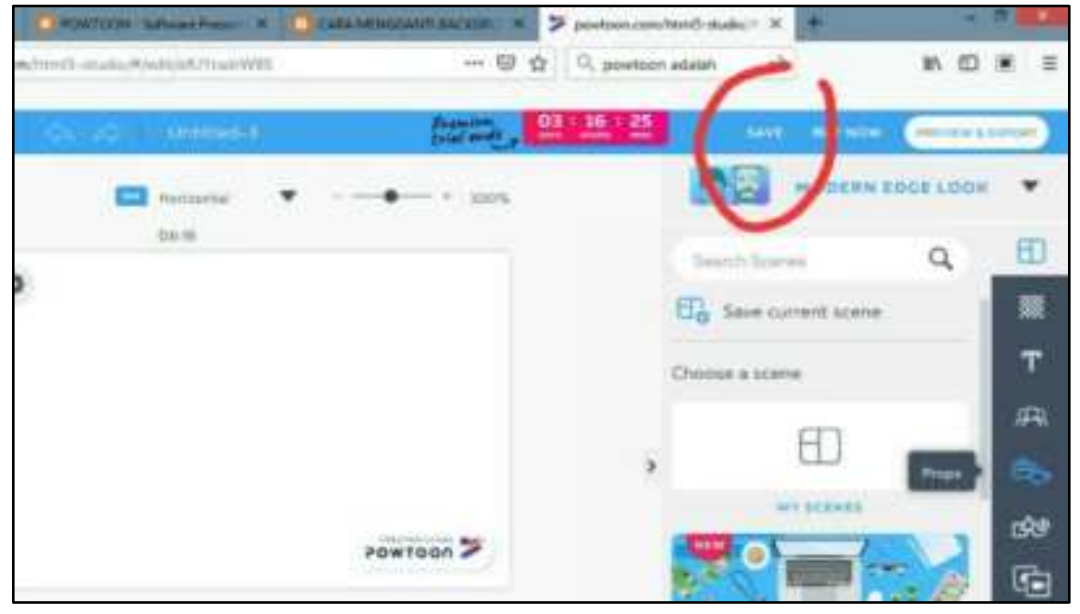

Gambar 6: Tampilan save pada Powtoon

12. Dengan demikian editing hasil video telah tersimpan dalam akun pengguna. Apabila ingin melakukan unggah video yang telah di buat, maka pengguna perlu kembali pada halaman 
laman awal. Caranya dengan meng-klik tanda panah arah ke kiri $(\leftarrow)$ yang terdapat pada bagian kiri atas tampilan layar.

13. Pada tampilan laman depan aplikasi powtoon, terdapat beberapa hasil video animasi yang telah dibuat. Scroll layar ke bawah atau klik My Powtoon untuk melihat semua hasil animasi. Tinggal memilih animasi tertentu untk diubah namanya terlebih dahulu, sebelum diunggah ke aplikasi atau website lain.

14. Untuk merubah nama video, temukan gambar pensil kemudian di klik. Ketik nama video sesuai keinginan pengguna.

15. Apabila pengguna akan mengunggah hasil animasi buatannya, klik tanda "export" yang terletak disebelah kanan gambar pensil (gambar 7).

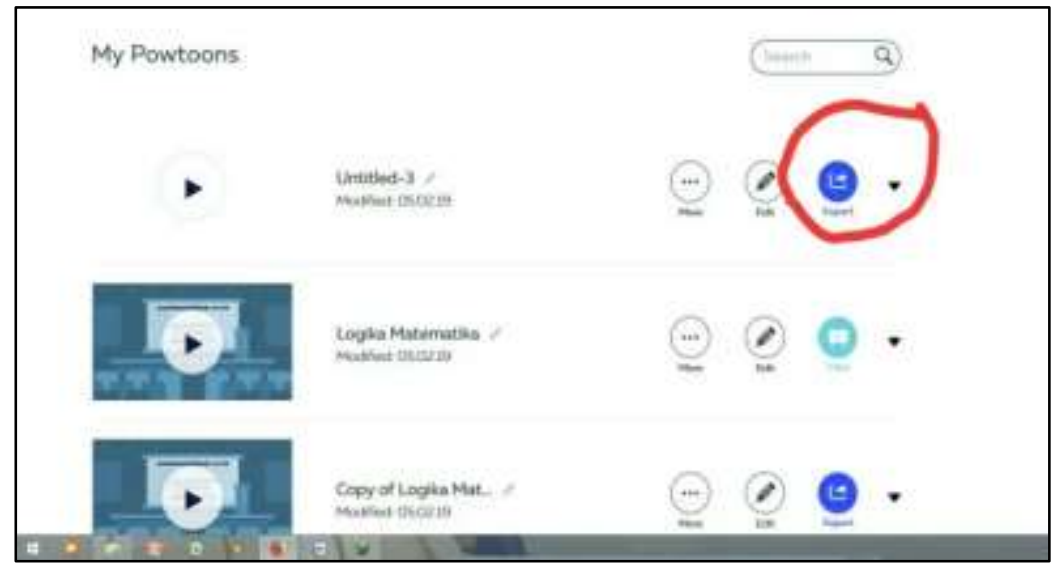

Gambar 7: Tampilan export pada video yang ingin di upload pada Powtoon

16. Setelah pengguna meng-klik export, akan muncul pilihan aplikasi dan website untuk tujuan unggah video animasi yang telah dibuat. Pengguna dapat memilih salah satu, kemudian klik dan selesai. Untuk proyek divisi inovasi pembelajaran daring ini, website tujuan unggah adalah Youtube..

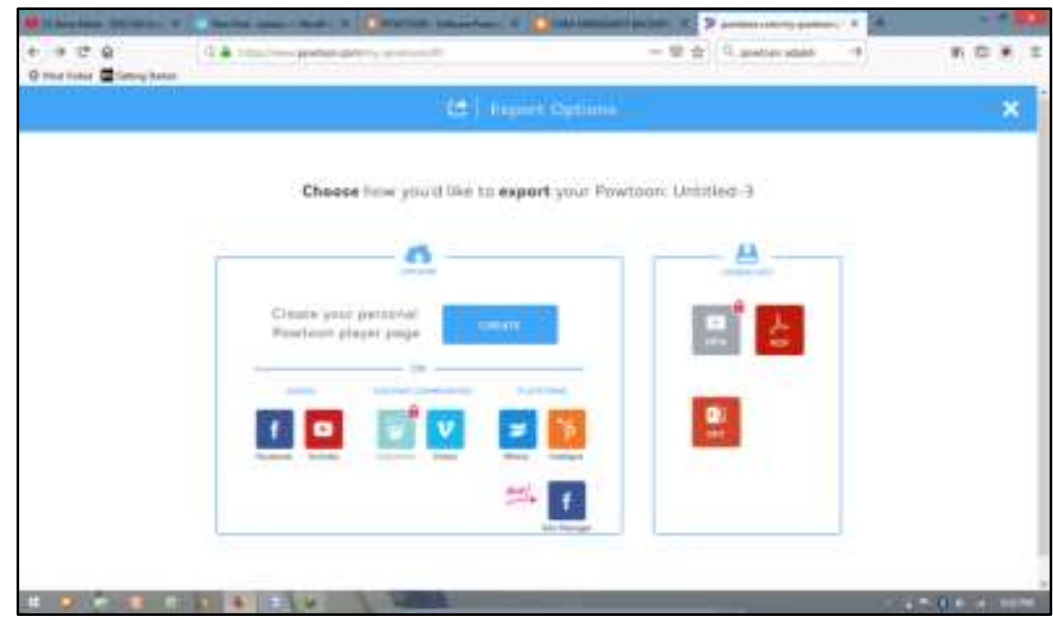

Gambar 8. Tampilan export pada Powtoon

\section{Tahap Pasca Produksi (Implementasi hasil)}

Setelah seluruh hasil video animasi diunggah di Youtube KKN Sidokumpul (KKN 45 Sidokumpul, 2020). Seluruh anggota tim dan DPL memberikan penjelasan kepada seluruh siswa SD dan orangtua melalui grup WhatsApp, tentang rencana pembelaran dan materi-materi yang 
sesuai dengan struktur silabus sekolah. Nomer WhatApp yang digunakan anak-anak, sebagian besar digunakan bersama dengan orangtuanya.

Gambar 9: Salah satu video animasi mata pelajaran Sains

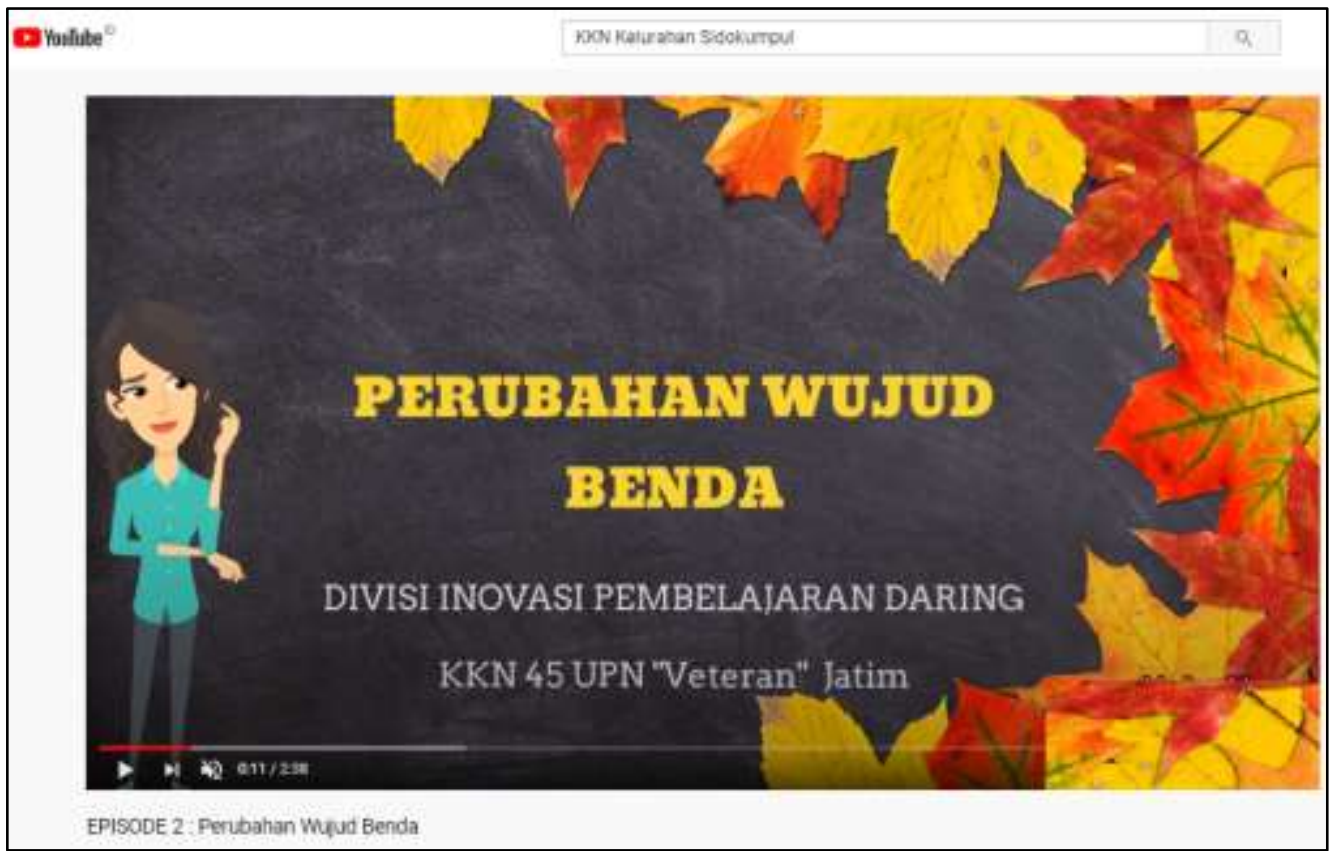

(https://www.youtube.com/watch?v=1eh1mZINtdU)

Tim divisi inovasi pembelajaran daring memberikan alamat link Youtube yang berisi video animasi, agar para siswa dan orang tua dapat mengakses video-video tertetu sesuai materi pembelajaran. Pada saat berlangsung sesi pembelajaran daring melalui WA, siswa diperkenankan didampingi orang tua untuk melakukan interaksi pada saat sesi tanya jawab. Tujuannya agar terjalin komunikasi antara orangtua dan anak tentang materi belajar dan agar siswa lebih mudah memahami materi yang diberikan. Setelah waktu mempelajari video (15 menit) dan pembelejaran daring selesai (20-30 menit) selesai, tim divisi inovasi pembelajaran daring membagikan google form yang berisikan pertanyaan seputar video animasi. Waktu yang disediakan untuk menjawab pertanyaan-pertanyaan tersebut adalah 15 menit. Hasil dari sesi tanya jawab di WA dan jawaban dari google form akan di akumulasi untuk mendapatkan data peserta paling aktif dan orangtua pendamping terbaik untuk diberi hadiah sebagai stimulus agar siswa semakin giat belajar.

Hasil pembelajaran selama satu bulan, kemudian dievaluasi secara bersama oleh tim divisi inovasi pembelajaran daring, Dosen Pembimbing Lapangan, dan Guru sekolah. Banyak hal positif yang layak mendapatkan perhatian agar program pembelajaran daring dengan video animasi mata pelajaran ujian nasional, antara lain: (1) para siswa sangat antusias untuk mempelajari materi berupa media audio visual. (2) para siswa menjadi lebih mudah memahami materi sesuai silabus mata pelajaran dan tidak bosan karena harus terus belajar dengan membaca buku. (3) para guru membutuhkan pelatihan khusus pembuatan video animasi sebagai inovasi pembelajaran. (4) keterlibatan orangtua dalam pembelajaran daring semakin mendekatkan komunikasi dengan anak-anak mereka. Pada kondisi pandemi COVID-19, orangtua memiliki peran sangat vital bagi keberhasilan belajar siswa karena menjadi pengganti guru ketika belajar dirumah (Mardliyah et al., 2020). Para orangtua berterimakasih karena dapat mengikuti aktivitas belajar sekaligus mengawasi penggunaan gawai oleh anak-anak mereka, agar anak-anak terlindungi dari perundungan, pornografi, penyebaran had, dan bijak 
bermedia sosial (Achmad et al., 2016; Alamiyah, 2020; Claretta et al., 2018; Tutiasri et al., 2019).

Perangkat desa, RT/RW, pengurus PKK, dan karang taruna mendukung kelancaran pembelajran daring melalui video animasi dengan menyediakan jaringan hotspot, hadiah (makanan sehat dan paket Sembako) bagi anak dan orangtua yang bekerjasama dengan baik selama pelaksanaan program. Pemberian hadiah sebagai reward atas aktivitas belajar anak dan orangtua menjadi penyemangat kompetisi belajar. Dalam konsep pendidikan, hadiah atau penghargaan merupakan salah satu alat untuk peningkatan motivasi para peserta didik. Metode ini bisa mengasosiasikan penghargaab atas perbuatan dan kelakuan baik seseorang, dan biasanya perasaan bahagia akan membuat orang tersebut akan perbuatan baik secara berulang-ulang. Penghargaan adalah unsur disiplin yang sangat penting dalam pengembangan diri dan tingkah laku anak. Seseorang akan terus berupaya meningkatkan dan mempertahankan disiplin apabila pelaksanaan disiplin itu menghasilkan prestasi dan produktivitas yang kemudian mendapatkan penghargaan. Dalam hal ini, guru atau pihak sekolah dapat bekerja sama dengan orangtua siswa dalam memberikan hadiah untuk siswa yang selama ini aktif dan semangat dalam mengikuti pembelajaran jarak jauh dan berhasil mendapatkan nilai baik di kelas (Kompri: 2016).

\section{Simpulan}

Inovasi pembelajaran pada masa pandemi COVID-19, untuk mata pelajaran ujian nasional (Bahasa Indonesia, Sains, dan Matematika) bagi siswa Sekolah Dasar, menjadi lebih mudah dipahami dengan menggunakan media pembelajaran video animasi. Pembuatan video animasi harus disesuaikan dengan silabus dan materi yang telah disusun dalam rencana pembelajaan. Media audio visual memiliki daya tarik bagi anak-anak usia SD dan memudahkan daya pemahaman siswa terhadap materi-materi pokok mata pelajaran.

Praktik inovasi pembelajaran melalui video animasi banyak tersedia di internet dan mudah dipelajari. Salah satunya adalah Powtoon, yang tidak membutuhkan waktu terlalu lama bagi guru untuk menguasai aplikasi pembuatan video animasi tersebut.

Pembelajaran daring dengan menyediakan banyak video animasi di Youtube dengan melibatkan partisipasi orangtua, memberikan berbagai hal positif bagi hubungan antar anggota keluarga dan perkembangan kepribadian anak. Serta melindungi anak dari berbagai pengaruh buruk atas kegunaan gadget dan akses konten berbahaya dari internet. Model pengabdian dengan inovasi pembelajaran daring melalui video animasi ini dapat direplikasi di daerah lain di Indonesia. Diperlukan sesi khusus bagi pelatihan pembuatan video animasi bagi guru-guru Sekolah Dasar. Bentuk dukungan dari pihak aparat kelurahan, pengurus PKK dan karangtaruna di Kelurahan Sidokumpul dapat dijadikan contoh kerja sama yang baik dalam mengatasai masalah pendidikan di daerah-daerah terdampak COVID-19.

\section{Ucapan Terima Kasih}

Tim divisi pembelajaran kelompok KKN 45 di Kelurahan Sidokumpul, Kecamatan Gresik, Kabupaten Gresik menyampaikan ucapan terima kasih kepada: (1) Pusat Pengabdian Masyarakat dan KKN, LPPM Universitas Pembangunan Nasional Veteran Jawa Timur. (2) Seluruh orang tua siswa, guru, dan siswa Sekolah Dasar di Kelurahan Sidokumpul. (3) Kepala 
Kelurahan Sidokumpul beserta seluruh perangkatnya, para pengurus PKK, dan pengurus Karang Taruna yang telah bekerja sama dengan para penulis selama melakukan penelitian

\section{Daftar Pustaka}

Achmad., Z. A. (2019). Integrasi Program Dakwah dan Budaya: Studi Etnografi Virtual Mediamorfosis Radio Nada FM Sumenep Madura. Jurnal Komunikasi Islam, 09(2), 238-263. https://doi.org/10.15642/jki.2019.9.2.239263

Achmad, Z. A. (2020). REVIEW BUKU: Mediamorphosis: Understanding New Media by Roger Fidler, Thousand Oaks, California: Pine Forge Press (2003). In E. R. Nawangsari \& A. Kriswibowo (Eds.), Potret Masyarakat dan Kebijakan Pemerintah dalam Menghadapi Tantangan Pandemi COVID-19. Program Studi Ilmu Administrasi Negara, UPN “Veteran” Jawa Timur.

Achmad, Z. A., Wiranata, I. M. A., \& Mardliyah, S. (2016). Teenagers are Subjected to Cyber Bullying in Social Media Ask.fm. RE-EXAMINING GOVERNANCE: STRENGTHENING CITIZENSHIP IN THE CHANGING WORLD, ICOCSPA 2016, 435-441. https://doi.org/978-602-18461-4-8

Agustin, M., Setiyadi, R., \& Puspita, R. D. (2020). BURNOUT PROFILE OF ELEMENTARY SCHOOL TEACHER EDUCATION STUDENTS (ESTES): FACTORS AND IMPLICATION OF GUIDANCE AND COUNSELING SERVICES. PrimaryEdu - Journal of Primary Education, 4(1), 38. https://doi.org/10.22460/pej.v4i1.1640

Alamiyah, S. S. (2020). 'I Become More Confident': Mother Use of Online Platform for Parenting Information. 423, 511-523. https://doi.org/10.2991/assehr.k.200325.039

Candrasari, Y. (2020). Mediated Interpersonal Communication: A New Way of Social Interaction in the Digital Age. Proceedings of the 2nd International Media Conference 2019 (IMC 2019). https://doi.org/10.2991/assehr.k.200325.041

Claretta, D., Candrasari, Y., \& Arianto, I. D. (2018). Mother's Strategy on Child Mentoring in Using the Internet. October, 357-363. https://doi.org/10.11594/nstp.2018.0152

Daulae, T. H. (2014). Menciptakan Pembelajaran yang Efektif. Forum Pedagogik, 06(02), 134.

Ernofalina, E. (2017). Culture Shocks Experienced by Indonesian Students Studying Overseas. International Journal of Educational Best Practices, 1(2), 87. https://doi.org/10.31258/ijebp.v1n2.p87-105

Gikas, J., \& Grant, M. M. (2013). Mobile computing devices in higher education: Student perspectives on learning with cellphones, smartphones \&amp; social media. The Internet and Higher Education, 19, 18-26. https://doi.org/10.1016/j.iheduc.2013.06.002

Gore, J., Lloyd, A., Smith, M., Bowe, J., Ellis, H., \& Lubans, D. (2017). Effects of professional development on the quality of teaching: Results from a randomised controlled trial of Quality Teaching Rounds. Teaching and Teacher Education, 68, 99-113. https://doi.org/10.1016/j.tate.2017.08.007

Indiyati, D., Chotijah, S., Khusnia, H. N., \& Muhlis, M. (2020). Media vs public trust during the pandemic. JCommsci - Journal Of Media and Communication Science, 1(1), 38-44. https://doi.org/10.29303/jcommsci.v1i1.95

KKN $45 \quad$ Sidokumpul. (2020). Perubahan Wujud Benda. YouTube. https://www.youtube.com/watch?v=1eh1mZINtdU

Mardliyah, S., \& Achmad, Z. A. (2017). Binary Opposition in the Educational Study in Indonesia: Non Formal Education Deconstructs Formal Education. International Conference on Education Innovation (ICEI), 772777.

Mardliyah, S., Yulianingsih, W., \& Putri, L. S. R. (2020). Sekolah Keluarga: Menciptakan Lingkungan Sosial untuk Membangun Empati dan Kreativitas Anak Usia Dini. Jurnal Obsesi : Jurnal Pendidikan Anak Usia Dini, 5(1), 576. https://doi.org/10.31004/obsesi.v5i1.665

Moore, J. L., Dickson-Deane, C., \& Galyen, K. (2011). e-Learning, online learning, and distance learning environments: Are they the same? The Internet and Higher Education, 14(2), 129-135. https://doi.org/10.1016/j.iheduc.2010.10.001

Mushlihah, K., Yetri, Y., \& Yuberti, Y. (2018). Pengembangan Media Pembelajaran Berbasis Multi Representasi 
Bermuatan Sains Keislaman dengan Output Instagram pada Materi Hukum Newton. Indonesian Journal of Science and Mathematics Education, 1(3), 207-215. https://doi.org/10.24042/ijsme.v1i3.3595

Nurkamid, M., Dahlan, M., Susanto, A., \& Khotimah, T. (2010). Pemanfaatan aplikasi jejaring sosial facebook untuk media pembelajaran. Jurnal Sains Dan Teknologi, 3(2), 1-16.

Panjaitan, N. Q., Yetti, E., \& Nurani, Y. (2020). Pengaruh Media Pembelajaran Digital Animasi dan Kepercayaan Diri terhadap Hasil Belajar Pendidikan Agama Islam Anak. Jurnal Obsesi : Jurnal Pendidikan Anak Usia Dini, 4(2), 588. https://doi.org/10.31004/obsesi.v4i2.404

Ronkainen, R., Kuusisto, E., \& Tirri, K. (2019). Growth Mindset in Teaching: A Case Study of a Finnish Elementary School Teacher. International Journal of Learning, Teaching and Educational Research, 18(8), 141-154. https://doi.org/10.26803/ijlter.18.8.9

Rubiyati, Muhamad Asrori, L. W. (2017). Pengaruh Pemanfaatan Media Sosial Instagram Terhadap Kreativitas Belajar Pada Remaja Kelas VII. Jurnal Untan, 1-8. http://jurnal.untan.ac.id/index.php/jpdpb/article/download/25681/75676576765

Setyosari, P. (2017). MENCIPTAKAN PEMBELAJARAN YANG EFEKTIF DAN BERKUALITAS. JINOTEP (Jurnal Inovasi Dan Teknologi Pembelajaran) Kajian Dan Riset Dalam Teknologi Pembelajaran, 1(5), 20-30. https://doi.org/10.17977/um031v1i12014p020

Teluma, A. R. L. (2020). Membaca Realitas Infodemi Covid-19 di Indonesia. JCommsci - Journal Of Media and Communication Science, 1(1), 1. https://doi.org/10.29303/jcommsci.v1i1.91

Tutiasri, R. P., Kusuma, A., \& Sumardjijati, S. (2019). Perilaku Remaja dalam Penyebaran Hoax di Grup WhatsApp. Jurnal IImu Komunikasi, 2(1). https://doi.org/10.33005/jkom.v2i1.36

Yulianingsih, W., Artha, I. K., \& Mardliyah, S. (2018). Lifelong Learning as a Response toward Learning Society. Proceedings of the 1st International Conference on Education Innovation (ICEI 2017). https://doi.org/10.2991/icei-17.2018.99

Yusuf, B. B. (2017). Konsep Dan Indikator Pembelajaran Efektif. Jurnal Kajian Pembelajaran Dan Keilmuan, 1(1), 13 20. http://jurnal.untan.ac.id/index.php/jurnalkpk/article/view/25082/75676576424 